\title{
Interaction Study Between Humin and Phosphate: Possible Environmental Remediation for Domestic Wastewater
}

\author{
Daniella Araujo Vasconcelos de Oliveira - Wander Gustavo Botero • \\ Josué Carinhanha Caldas Santos • Ricardo Moutinho da Silva • \\ Leonardo Machado Pitombo • Janaina Braga do Carmo • \\ Luana Maria Tavares Rosa • Luciana Camargo de Oliveira
}

Received: 14 March 2017 / Accepted: 23 June 2017 / Published online: 6 July 2017

(C) Springer International Publishing AG 2017

\begin{abstract}
The increase in demand for food due to the rapid population growth in recent years has raised the use of fertilizers, particularly phosphate salts. This fact has contributed to the excess amount of phosphorus species in aquatic systems. This is due to the leaching of these species present in the fertilizers applied to the soil to aquatic environments and may lead to eutrophication in these environments. Substances capable of interacting with the phosphate in the aquatic environment are promising for the reduction on the environmental impact. The humin, an insoluble fraction of humic material, has potential for phosphate retention, behaving like a chelating resin. Thus, the purpose of this research was to study the interaction between humin and phosphate. The equilibrium time between humin and
\end{abstract}

D. A. V. de Oliveira • L. M. Pitombo

Federal University of São Carlos (UFSCar), Sorocaba, SP

18.052-780, Brazil

W. G. Botero • J. C. C. Santos

Post-graduate Program in Chemistry and Biotechnology, NCEX/ PPGQB/UFAL at the Federal University of Alagoas (UFAL), CP 61, Arapiraca 57.309-005, Brazil

R. M. da Silva

Department of Analytical Chemistry, Institute of Chemistry, São Paulo State University (UNESP), CP 355, Araraquara, SP 14801-970, Brazil

J. B. do Carmo • L. M. T. Rosa • L. C. de Oliveira $(\bowtie)$ Post-graduate Program in Biotechnology and Environmental Monitoring, PPGBMA at the Federal University of São Carlos (UFSCar), Sorocaba, SP 18.052-780, Brazil e-mail: lcamargo@ufscar.br phosphate was $15 \mathrm{~min}$, where hydrogenionic potential (pH) 4.0 was the most effective in the interaction process. In this $\mathrm{pH}$, the humin retained $33 \%$ of phosphate added. The complexing capacity of the huminphosphate system was $11.53 \mathrm{mg} \mathrm{g}^{-1}$. The adsorption studies indicated that the system follows a kinetic pseudo-second-order model. The Freundlich model was the most suitable to describe the phosphate adsorption process in humin. To evaluate the humin application in real systems, humin was added to the domestic wastewater. Sixteen percent of the total phosphate was adsorbed by the humin. Based on these results, humin has the potential to phosphate retention in domestic wastewater and could be used as a chelating resin minimizing environmental impact.

Keywords Humin · Phosphate - Complexing capacity Adsorption · Wastewater

\section{Introduction}

Phosphate substances are found widely in industrial, domestic, and agricultural sectors. The final destination of these substances is the water sources, which could cause serious water pollution problems. Although phosphate and other phosphorus species are not considered toxic, as a nutrient, they may be responsible for nutritional enrichment of water sources, promoting excessive algae growth and causing eutrophication (Millier and Hooda 2011). 
For many years, the control of phosphorus and their species in surface water was directed to point sources related to phosphate detergents and domestic wastewater. Currently, the impact of diffuse sources has been questioned. The large annual input caused by the introduction of phosphate fertilizers and no removal of this leached phosphate to water sources causes a high environmental impact (Manahan and Manahan 2009). For this reason, the use of substances that interact with the different phosphorus species, including natural fertilizers, is the most appropriate to reduce environmental impact (Winarso et al. 2011).

Humic substances (HS) are promising to fulfill this dual function, due to diversity of functional groups present in its structure (Botero et al. 2010; Rocha et al. 2009; Sargentini et al. 2001; Winarso et al. 2011). The humin, an insoluble fraction of HS, is the most resistant fraction to microbial degradation and considered the last product of the humidification process. This fraction of HS presents different functional groups in their structure such as esters, methoxy alkanes, polar aromatic groups, and sugar derivatives (De La Rosa et al. 2003). Also, by presenting high porosity with large surface areas, it becomes a potential adsorbent for applications in retention processes (Contreras et al. 2006).

The humin, the fraction of humic substances less studied, plays an important role in the interaction with organic and inorganic species (Cerqueira et al. 2012; De La Rosa et al. 2003; Nkhili et al. 2012; Rice 2001; Winarso et al. 2011; Zhang et al. 2009). Given the high input of phosphorus species in water sources and their importance to agriculture, this study aimed to evaluate the use of humin in phosphate removal present in domestic wastewater.

\section{Material and Methods}

\subsection{Reagents}

The diluted acidic and alkaline solutions required for the humin sample extraction were prepared from the appropriate dilution of hydrochloric acid $37 \%(\mathrm{~m} / \mathrm{m})$ $0.1 \mathrm{~mol} \mathrm{~L}^{-1}$ (Suprapur, Merck AG) or sodium hydroxide $0.1 \mathrm{~mol} \mathrm{~L}^{-1}$ (Suprapur, Merck AG) in purified water with conductivity less than $0.1 \mu \mathrm{S} \mathrm{cm}^{-1}$ (Milli-Q, Millipore). All reagents used are of high purity.

\subsection{Procedures and Methods}

\subsubsection{Humin Extraction}

Soil samples were collected near the Mogi River in the city of Ribeirão Preto, São Paulo State, Brazil. The main characteristic of these soil samples is the high organic matter contents. The extraction of humin fraction was carried out according to the most common method used by researchers associated with the International Humic Substances Society (IHSS). The extraction solution of $\mathrm{NaOH} 0.10 \mathrm{~mol} \mathrm{~L}^{-1}$ was used at 1:10 soil/extractor under inert $\mathrm{N}_{2}$ atmosphere and submitted to mechanical agitation for $4 \mathrm{~h}$ (Botero et al. 2013; Rosa et al. 2000). After extraction, the humin (insoluble fraction) was separated by centrifugation and washed with an excess of distilled water to remove residual alkalinity and organic matter from the extraction process. Finally, it was dried in an oven at $55{ }^{\circ} \mathrm{C}$ to constant weight (Goveia et al. 2013).

\subsubsection{Zero Point Charge}

The $\mathrm{pH}$ of a solution of $0.01 \mathrm{M} \mathrm{NaCl}$ was adjusted to between 2 and 12 by adding either $\mathrm{HCl} 0.1 \mathrm{~mol} \mathrm{~L}^{-1}$ or $\mathrm{NaOH} 0.1 \mathrm{~mol} \mathrm{~L}^{-1}$. Nitrogen was bubbled through the solution at $25{ }^{\circ} \mathrm{C}$ to remove any dissolved carbon dioxide until the initial $\mathrm{pH}$ stabilized. Humin samples $(0.15 \mathrm{~g})$ were added to $50 \mathrm{~mL}$ of each solution. After $24 \mathrm{~h}$, the final $\mathrm{pH}$ was recorded. To determine the $\mathrm{pH}$ corresponding to zero point charge, graphs of $\mathrm{pH}$ variation $(\Delta \mathrm{pH})$ in function of initial $\mathrm{pH}$ were plotted, and the intersection with the $x$-axis represents the zero point charge (Batista et al. 2009).

\subsubsection{Determination of Phosphate}

The molybdenum blue spectrophotometric method was used to determine the total concentration of phosphate (Raij et al. 1987). The measurements were performed at $660 \mathrm{~nm}$ with a linear range from 0.5 to $10.0 \mathrm{mg} \mathrm{L}^{-1}$ in phosphate solution $(r=0.9989)$.

\subsubsection{The Influence of $\mathrm{pH}$ and Time in Humin-Phosphate Interaction}

In order to evaluate the effect of $\mathrm{pH}$ and time on the humin-phosphate interaction, $50 \mathrm{~mL}$ of phosphate stock solution of $10 \mathrm{mg} \mathrm{L}^{-1}$ in $100 \mathrm{mg}$ humin at $\mathrm{pH}$ 4.0, 6.0, 
and 8.0 was added. The system was kept in agitation five times for 10, 15, 30, 120, and $180 \mathrm{~min}$ (Jacundino et al. 2015) After agitation, samples were filtered through a $0.45-\mu \mathrm{M}$ membrane. The supernatant was quantified spectrophotometrically using the molybdenum blue method (Raij et al. 1987).

\subsubsection{Ultrafiltration Procedure Used for Kinetic Study}

The determination of the equilibrium time related to the humin-phosphate interaction was performed using an ultrafiltration tangential flow system equipped with a 1-kDa membrane porosity (Burba et al. 2001; Romao et al. 2003). In this system, the phosphate which passes through the filter refers to a level not interacting with the humin. Thus, a solution containing $300 \mathrm{mg}$ of humin at $\mathrm{pH} 4.0$ was homogenized for $5 \mathrm{~min}$, where the first filtration is referred to the phosphate originally present in humin. Then, the phosphate solution was added at a concentration of $100 \mathrm{mg} \mathrm{L}^{-1}$ and filtrations were done at 15-min intervals.

\subsubsection{Determination of Complexing Capacity of Humin-Phosphate System}

The determination of the complexing capacity of the humin phosphate was conducted using an ultrafiltration tangential flow system (Burba et al. 2001; Romao et al. 2003). After the first filtration without the addition of phosphate, increasing amounts of analyte were added with the purpose of having phosphate concentrations ranging from 0.124 to $82.00 \mathrm{mg} \mathrm{L}^{-1}$. After each addition, the system was stirred for $20 \mathrm{~min}$ (equilibrium time) and filtered to determine the amount of phosphate not retained by humin.

\subsubsection{Evaluation of the Kinetic and Adsorption Isotherm Models}

The evaluation of the kinetic and adsorption processes of humin against phosphate was performed using $100 \mathrm{mg}$ of humin. In the kinetic studies, the time range evaluated was 5 to $180 \mathrm{~min}$, adding a phosphate concentration of $12 \mathrm{mg} \mathrm{L}^{-1}$ in three different $\mathrm{pH}$ values

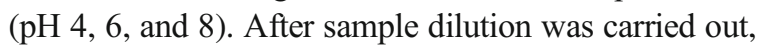
free phosphate was determined by molybdenum blue spectrophotometry.

To determine the isotherm adsorption which best describes phosphate and humin, the system was performed using phosphate solutions containing 1 to $100 \mathrm{mg} \mathrm{L}^{-1}$ at $\mathrm{pH} 4.0$ (Jacundino et al. 2015). After agitation for $20 \mathrm{~min}$, the samples were filtered through $0.45-\mu \mathrm{m}$ membranes and the remaining phosphate content was determined by the method described in Sect. 2.2.3 (Souza et al. 2016).

\subsubsection{Phosphate Speciation Model}

In this study, simulations using Visual MINTEQ 3.1 software was performed for phosphate speciation at different $\mathrm{pH}$ values $(0.0-14.0)$. This software can be used for calculation of elemental species distribution (\%), solubility equilibria, and sorption mechanisms. The simulations help to understand the ionic species available in solution during the interaction between humin and phosphate (Gustafsson 2016).

\subsubsection{Application of Humin in Domestic Effluent Samples}

In order to assess the application of humin as adsorbent in real systems, we added $50 \mathrm{~mL}$ of domestic wastewater collected in a sewage treatment station in São Paulo State, Brazil, in $100 \mathrm{mg}$ of humin. The samples were agitated for $5,10,15,30,120$, and $180 \mathrm{~min}$ and subsequently filtered through a $0.45-\mu \mathrm{M}$ membrane. The phosphate content was determined as described above. The efficiency of the adsorption was evaluated in the natural $\mathrm{pH}$ of effluent and at $\mathrm{pH} 4$.

\section{Results and Discussion}

\subsection{Characterization of Humin}

The humin used in this study was characterized previously, and the results were presented in Jacundino et al. (2015). The humin contains $27.5 \%$ of organic matter and $72.5 \%$ of inorganic matter, with an E4/E6 ratio equal to 1.15 . Furthermore, it has $33 \%$ aliphatic carbon $\left(\delta^{13} \mathrm{C}\right.$ NMR from 0 to $\left.65 \mathrm{ppm}\right), 13 \%$ ethers, hydroxylated functions, sugars ( $\delta^{13} \mathrm{C}$ NMR from 65 to $\left.110 \mathrm{ppm}\right)$, $33 \%$ aromatic carbon $\left(\delta^{13} \mathrm{C}\right.$ NMR from 110 to $140 \mathrm{ppm}), 9 \%$ of phenols $\left(\delta^{13} \mathrm{C}\right.$ NMR from 140 to $160 \mathrm{ppm})$, and $13 \%$ carboxylic acids $\left(\delta^{13} \mathrm{C}\right.$ NMR from 160 to $190 \mathrm{ppm}$ ) (Jacundino et al. 2015).

The results of humin characterization indicate a high degree of humification (Jacundino et al. 2015). 
According to studies, the $\mathrm{E}_{4} / \mathrm{E}_{6}$ ratio lower than 4 indicates more presence of condensed aromatic structures, increasing molar mass, and consequently a greater degree of humification to the humic material. The results of ${ }^{13} \mathrm{C}$ NMR indicate a high aromatic content corresponding to the results of the ratio $\mathrm{E}_{4} / \mathrm{E}_{6}$.

Finally, the charge distribution to humin in function of $\mathrm{pH}$ was determined from the zero point charge $\left(\mathrm{pH}_{\mathrm{ZPC}}\right)$ value, with a balance between negative and positive charges of the ionic groups. The $\mathrm{pH}_{Z P Z}$ obtained was 6.35 for humin. Thus, at $\mathrm{pH}$ values below the $\mathrm{pH}_{\mathrm{ZPZ}}$, the overall charge is positive, whereas at $\mathrm{pH}$ values higher than $\mathrm{pH}_{\mathrm{ZPZ}}$, a negative charge from humin was obtained. This parameter helps to understand the adsorptive processes between phosphate and humin.

\subsection{Influence of $\mathrm{pH}$ and Time on the Humin-Phosphate} Complexation Capacity

The phosphorus in natural wastewater is present almost exclusively in phosphate form (Standard Methods 2005). Depending on the $\mathrm{pH}$, the phosphate may be found in several protonation degrees (Fig. 1), which is common for species derived from weak acids and bases.

In this study, we evaluated the phosphate interaction with humin in $\mathrm{pH} 4.0,6.0$, and 8.0. It was performed because the objective was to verify the possibility of phosphate retention in wastewater for later use in agriculture. These studies include $\mathrm{pH}$ values of samples with environmental interests.

An evaluation on the distribution of $\mathrm{P}$ species as a function of $\mathrm{pH}$ values (Fig. 1a) was obtained from simulations carried out in Visual MINTEQ 3.1 software (Gustafsson 2016), allowing to observe the percentages of the main forms of phosphorus found in $\mathrm{pH} 4.0,6.0$, and 8.0 which are as follows: $98.5 \%$ of $\mathrm{H}_{2} \mathrm{PO}_{4}{ }^{-}$and $1.5 \%$ of $\mathrm{H}_{3} \mathrm{PO}_{4}$ (pH 4.0), $94 \%$ of $\mathrm{H}_{2} \mathrm{PO}_{4}{ }^{-}$and $\mathrm{HPO}_{4}{ }^{2-}$ of $6 \%\left(\mathrm{pH} 6.0\right.$ ), and $13.6 \%$ to $86.4 \%$ of $\mathrm{H}_{2} \mathrm{PO}_{4}{ }^{-}$and $\mathrm{HPO}_{4}{ }^{2-}$ ( $\left.\mathrm{pH} 8.0\right)$.

The evaluation of species distribution in the medium is critical for interaction studies such as macrostructures such as humin, which has a diversity of available functional groups. Please note that the two species with a higher phosphate concentration in the medium are $\mathrm{H}_{2} \mathrm{PO}_{4}{ }^{-}$and $\mathrm{HPO}_{4}{ }^{2-}$ which exhibit different interaction sites on the protonation degree (Fig. 1b). The $\mathrm{H}_{2} \mathrm{PO}_{4}{ }^{-}$ species have more sites to form hydrogen bonds while $\mathrm{HPO}_{4}{ }^{2-}$ species have preferred interaction sites by electrostatic strength.
Based on Fig. 2, the stabilization of phosphate retention occurs after 15 min of contact between humin and phosphate, regardless of the $\mathrm{pH}$ values. The amount of adsorbed phosphate by humin was calculated from the difference between the initial and final concentrations as described in Eq. 1:

$q=\frac{\left(C_{0}-C\right) \times \mathrm{V}}{m}$

According to Eq. 1, $q$ is the amount of phosphate (mg) adsorbed by humin (g) based on dry mass ( $\mathrm{mg} \mathrm{g}^{-1}$ humin), $C_{0}$ and $C$ are the initial and final phosphate concentrations $\left(\mathrm{mg} \mathrm{L}^{-1}\right)$, respectively, $V$ is the volume of the final solution, and $m$ is the adsorbent mass (g) (Souza et al. 2016; Goveia et al. 2013).

The highest phosphate retention in the humin occurs at $\mathrm{pH} 4.0$ equivalent to $32 \%$ of the total phosphate present in the solution. At $\mathrm{pH} 4.0$, the predominant form of inorganic phosphorus is $\mathrm{H}_{2} \mathrm{PO}_{4}^{-}$(Fig. 1a). $\mathrm{H}_{2} \mathrm{PO}_{4}{ }^{-}$ has a negative charge; thus, if the humin surface is also negative, electrostatic repulsion can occur between $\mathrm{H}_{2} \mathrm{PO}_{4}{ }^{-}$and humin, reducing the interaction degree (Paula Filho and Marins 2004). However, at $\mathrm{pH} 4.0$ comparing $\mathrm{H}_{2} \mathrm{PO}_{4}{ }^{-}$and $\mathrm{HPO}_{4}{ }^{2-}$, it is noted that the species $\mathrm{H}_{2} \mathrm{PO}_{4}{ }^{-}$has a higher number of hydroxyl (Fig. 1b) and less negative charge, and therefore has less repulsion capacity and a higher ability to form hydrogen bonds inferring in a higher interaction capacity with humin. Moreover, the result of $\mathrm{pH}_{\mathrm{PZC}}$ was 6.35; thus, at $\mathrm{pH} 4.0$ the humin surface preferably has a positive charge, favoring the interaction process with $\mathrm{H}_{2} \mathrm{PO}_{4}{ }^{-}$by electrostatic forces.

The humin-phosphate system at $\mathrm{pH} 8.0$ showed retention by $12 \%$ of the total phosphate, while at $\mathrm{pH} 6.0$ the retention was $10 \%$. However, at $\mathrm{pH} 8.0$ there are higher levels of $\mathrm{HPO}_{4}{ }^{2-}$ than $\mathrm{H}_{2} \mathrm{PO}_{4}{ }^{-}$, suggesting that in basic medium possible changes on the humin surface may occur, favoring its greater interaction. According to Manahan and Manahan (2009), at higher $\mathrm{pH}$ values, the surface metal oxides have a negative net charge due to the presence of hydroxyl $\left(\mathrm{OH}^{-}\right)$. In this case, the anions $\mathrm{HPO}_{4}{ }^{2-}$ are favored during the interaction with metal oxides due to its capacity to move hydroxyls directly connected to the material surface. As humin mostly has inorganic particles in its composition (72.5\%), it can have similar adsorption behavior that occurs on the metal oxide surfaces. Thus, it is suggested that the phosphate ions can be adsorbed on the surface of humin 
b

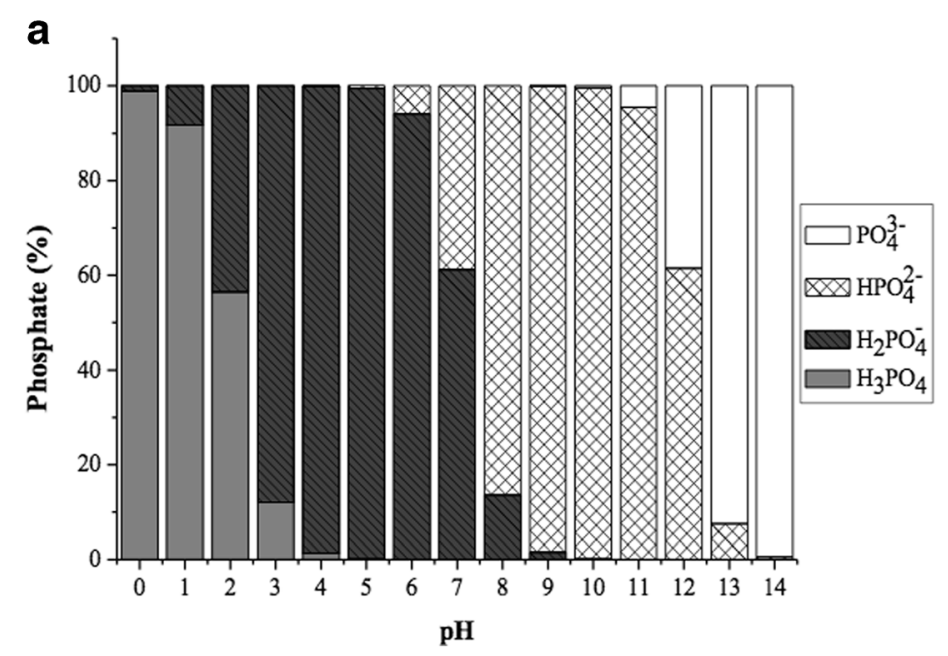

Fig. 1 a Phosphate species distribution as a function of $\mathrm{pH}$ using Visual MINTEQ 3.1 software. b Balance between the phosphate

by the displacement of hydroxyl ions. In addition, for $\mathrm{pH}$ values higher than $\mathrm{pH}_{\mathrm{PZC}}$ values, the surface of humin has a negative net charge due to the presence of hydroxyl ions, which corroborates with the proposed model and which justifies that the interaction process is more effective at $\mathrm{pH}$ 4.0.

\subsection{Humin Complexing Capacity by Phosphate}

The complexing capacity of natural materials such as humic substances, humin, and humic and fulvic acids has been evaluated as an important characteristic to understand the capacity of these substances in potentially complex toxic species or nutrients (Botero et al. 2013;

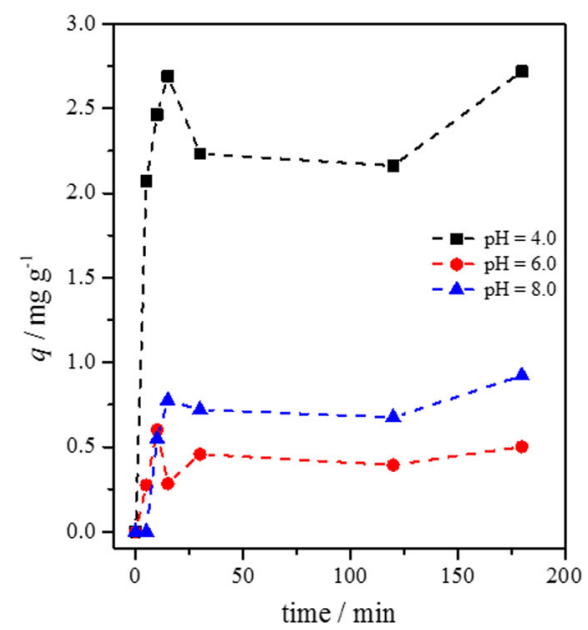

Fig. 2 Phosphate adsorption kinetics by humin at $\mathrm{pH} 4,6$, and 8 species in greater proportion in the middle and the possible interactions that they can do

Buffle and Staub 1984; Burba et al. 2001; Ninfant'eva et al. 1999). The complexing capacity (CC) is usually expressed in relation to the quantity of analyte that saturates the humin interaction sites. The $\mathrm{CC}$ is influenced by factors such as concentration of humic material (adsorbent), the species concentration to be complexed (adsorbed), $\mathrm{pH}$, temperature, ionic strengths, and other aspects (Botero et al. 2010; Rocha et al. 2009; Cunha et al. 2015; Souza et al. 2016).

Several techniques have been used in determining the complexing capacity such voltammetry, potentiometry, ultrafiltration, and chromatography. The advantage of ultrafiltration over other analytical strategies is associated with their versatility. The ultrafiltration can be used independent of the adsorbent or adsorbed material taking into consideration the organic or inorganic material which is due to the separation method of a physical process, allowing its use at different $\mathrm{pH}$ and ionic strengths (Burba et al. 2001; Buffle and Staub 1984; Ninfant'eva et al. 1999).

The humin complexing capacity by phosphate (Fig. 3) was determined by the intersection of the two curves related to the concentration of free (not binding the humin) and total inorganic phosphate (Botero et al. 2010), considering the parameter equal to $11.53 \mathrm{mg}$ of phosphate per gram of humin.

Botero et al. (2010) determined that the $\mathrm{CC}$ for samples of humic substances of peat obtained values of $8.73 \mathrm{mg} \mathrm{g}^{-1}$ for $\mathrm{Cu}(\mathrm{II})$, while Rosa et al. (2006) had obtained $16.21 \mathrm{mg} \mathrm{g}^{-1}$ for aquatic humic substances. When comparing anionic species, the $\mathrm{CC}$ values 


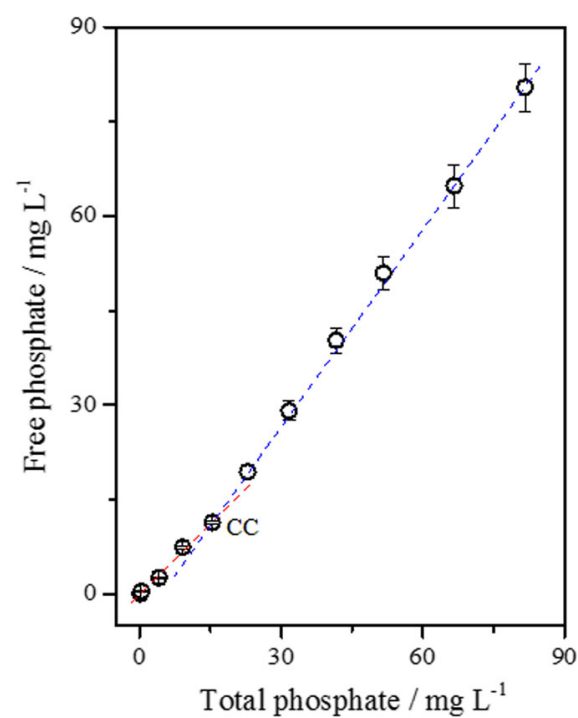

Fig. 3 Humin complexing capacity with phosphate

determined for phosphate ions in this study were higher than those determined by Souza et al. (2014) to humic substances from soil and water with $\mathrm{CN}^{-}$ions (3.69 and $7.2 \mathrm{mg} \mathrm{g}^{-1}$, respectively). Considering this comparison, it can be inferred that phosphate ions presents a high complexing capacity by humin.

\subsection{Kinetics Adsorption System of Phosphate and Humin}

The time dependence of adsorption on solid surfaces is known as adsorption kinetics, which varies according to particle size, analyte concentration, pressure, temperature, and adsorption affinity. In order to establish an equilibrium time for maximum adsorption, different mathematical models have been used to explain the adsorption kinetics of different species of organic matter fractions (Souza et al. 2016).

Normally, simple kinetic models are not used to represent adsorption on non-homogeneous surfaces because the transport phenomena and chemical reactions in these systems are indistinguishable experimentally. Thus, for these cases, kinetic equations such as pseudofirst and pseudo-second order are used (Ho and McKay 1999). On the other hand, the sorption diffusion process can be described by four consecutive steps: (i) transport in the bulk of the solution; (ii) diffusion across the liquid film surrounding the sorbent particles; (iii) particle diffusion in the liquid contained in the adsorbent pores and in the sorbate along the pore walls; and (iv) sorption and desorption within the particle and on the external surface. In these situations, the kinetic model based on intraparticle diffusion was employed (Ho et al. 2000). Therefore, the results were evaluated against three kinetic models to evaluate a better process description about the phosphate and humin system (Table 1). For the three kinetic models applied in this study, the kinetic of the pseudo-first-order model, the pseudo-secondorder model, and intraparticle diffusion, the linearization of the models were performed.

The pseudo-first-order model known as Lagergren equation (Eq. 2) says that the rate of removal of the substance adsorbed over time is directly proportional to the saturation and the number of active sites of the substance being represented by the following equation in linear form:

$\ln \left(q_{e}-q_{t}\right)=\ln \left(q_{e}\right)-k_{1} t$

where $q_{e}$ is the amount of the adsorbed substance $\left(\mathrm{mg} \mathrm{g}^{-1}\right)$ in equilibrium, $t$ is the time in minutes, $q_{t}$ is the amount of the substance $\left(\mathrm{mg} \mathrm{g}^{-1}\right)$ in a determined time (minutes), and $k_{1}$ is the constant of adsorption rate (Souza et al. 2016).

The pseudo-second-order model in linear form (Eq. 3 ) shows that the reaction rate is dependent on the amount of adsorbed solute on the adsorbent surface and the adsorbed amount at equilibrium. This model is represented by the following equation:

$$
\left(\frac{t}{q_{t}}\right)=\left(\frac{1}{k_{2} q_{e}^{2}}\right)+\left(\frac{1}{q_{e}}\right) t
$$

where $k_{2}$ is the constant rate of the pseudo-second-order model (Bagda et al. 2013).

The intraparticle diffusion model (Eq. 4) was applied to evaluate the mechanism of kinetics obtained. This model is characterized when the speed determinant factor and the adsorbant removal vary with the square root of time, described by

$q_{t}=k_{\mathrm{P}} t^{0.5}+C$

where $k_{P}$ is the intraparticle diffusion constant $\left(\mathrm{mg} \mathrm{g}^{-1} \min ^{-0.5}\right), C$ is a constant related to the diffusion resistance $\left(\mathrm{mg} \mathrm{g}^{-1}\right)$, and $q_{t}$ is the adsorbed amount $\left(\mathrm{g}^{-1} \mathrm{mg}\right)$ at time $t(\mathrm{~min})$.

Based on the results of Table 1, it was verified that the $\mathrm{pH}$ constitutes a parameter that influences the adsorption kinetics, independent of the model. At $\mathrm{pH} 4.0$, the kinetic of adsorption was more favorable, possibly due to the high concentration of $\mathrm{H}_{2} \mathrm{PO}_{4}{ }^{-}$ 
Table 1 Kinetic parameters for the adsorption process between humin and phosphate based on linear form models

\begin{tabular}{|c|c|c|c|c|c|c|c|c|c|c|}
\hline \multirow[t]{2}{*}{$\mathrm{pH}$} & \multirow{2}{*}{$\begin{array}{l}q \exp \\
\left(\mathrm{mg} \mathrm{g}^{-1}\right)\end{array}$} & \multicolumn{3}{|c|}{ Pseudo-first order } & \multicolumn{3}{|c|}{ Pseudo-second order } & \multicolumn{3}{|c|}{ Intraparticle diffusion } \\
\hline & & $\begin{array}{l}q_{e} \\
\left(\mathrm{mg} \mathrm{g}^{-1}\right)\end{array}$ & $k_{1}\left(\min ^{-1}\right)$ & $r$ & $\begin{array}{l}q_{e} \\
\left(\mathrm{mg} \mathrm{g}^{-1}\right)\end{array}$ & $\begin{array}{l}k_{2}(\mathrm{~g} \\
\left.\mathrm{mg}^{-1} \mathrm{~m} \mathrm{in}^{-1}\right)\end{array}$ & $r$ & $\begin{array}{l}k_{\mathrm{P}} \\
\left(\mathrm{mg} \mathrm{g}^{-1} \min ^{-0.5}\right)\end{array}$ & $\begin{array}{l}C \\
\left(\mathrm{mg} \mathrm{g}^{-1}\right)\end{array}$ & $r$ \\
\hline 4.0 & 2.72 & 3.03 & $0.29 \pm 0.03$ & 0.9854 & 2.58 & $0.14 \pm 0.02$ & 0.9967 & $0.71 \pm 0.10$ & 1.45 & 0.9799 \\
\hline 6.0 & 0.60 & 1.91 & $0.04 \pm 0.01$ & 0.9474 & 0.52 & $0.09 \pm 0.01$ & 0.9858 & $0.08 \pm 0.01$ & 0.31 & 0.9613 \\
\hline 8.0 & 0.92 & 1.21 & $0.13 \pm 0.02$ & 0.9443 & 0.88 & $0.12 \pm 0.03$ & 0.9769 & $0.14 \pm 0.03$ & 0.59 & 0.9589 \\
\hline
\end{tabular}

specie in the solution, which has a higher number of hydroxyl and less negative charge, and therefore has less repulsion capacity and a higher ability to form hydrogen bonds with humin.

According to the results (Table 1), the kinetic model that best describes the experimental profile is the pseudo-second-order model taking into account a time of $180 \mathrm{~min}$. This can be observed due to its higher correlation coefficient $(r)$ indicating greater concordance between the results and the model. Furthermore, the smallest differences between the $q_{\exp }$ value and $q$ (calculated) was for this model. Another fact to be observed and previously shown is that at $\mathrm{pH} 4$, the $r$ values are the closest unit both in the pseudo-first-order model and in the pseudo-second-order model, indicating a better fit. In addition, in the pseudo-first-order model, the adsorption process occurs preferentially at high solute concentration; on the other hand, the pseudo-secondorder model is a characteristic of systems with low solute concentrations (Azizian 2004), which corresponds with the interaction process between phosphate and humin.

\subsection{Evaluation of Adsorption Isotherms}

The adsorption process can be described by different isotherm models. There are several adsorption models, but the most widely used for applications in water and wastewater treatment processes are the Langmuir and Freundlich isotherms. Figure 4 shows the graphic profile data for the phosphate system and humin, and Table 2 shows the calculated values for the mentioned isotherms.

The Langmuir isotherm is related to a monolayer of adsorbed substance in the homogeneous surface of the adsorbent containing identical sites and uniform adsorption energies. The Langmuir equation of the model is expressed by $q_{e}=q_{\max }\left[\left(K_{L} C_{e}\right) /\left(1+K_{L} C_{e}\right)\right]$

where $q_{\max }$ is the maximum amount of adsorbate retained on the solid material ( $\left.\mathrm{mg} \mathrm{g}^{-1}\right), K_{L}$ is the Langmuir constant related to the solute adsorption capacity $\left(\mathrm{L} \mathrm{mg}{ }^{-1}\right)$, and $C_{e}\left(\mathrm{mg} \mathrm{L}^{-1}\right)$ represents the phosphate concentration at equilibrium. Equation 5 can be linearized leading to Eq. 6:

$$
\left(C_{e} / q_{e}\right)=\left[\left(1 / q_{m}\right) C_{e}\right]+\left(1 / K_{L} q_{m}\right)
$$

The term $R_{L}$ is dimensional and related to the Langmuir model called separation factor, defined according to Eq. 7:

$R_{L}=\frac{1}{\left(1+K_{L} C\right)}$

where $C$ is the highest adsorbed concentration $\left(\mathrm{mg} \mathrm{L}^{-1}\right)$ and $K_{L}$ is the Langmuir constant. If the $R_{L}$ value is greater than 1 , it indicates that the process is

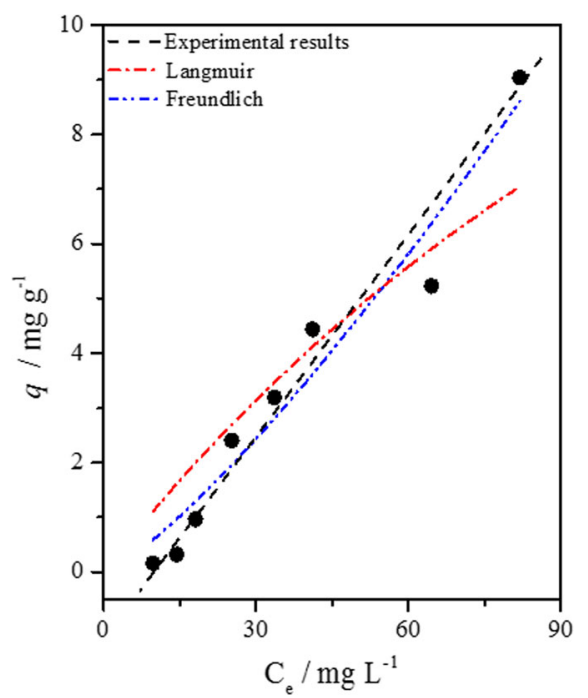

Fig. 4 Experimental data from adsorption isotherm models for phosphate system and humin 
Table 2 Main parameters of Langmuir and Freundlich isotherms for the phosphate system and humin at pH 4

\begin{tabular}{|c|c|c|c|c|c|c|c|}
\hline \multirow[t]{2}{*}{$q_{\exp }\left(\mathrm{mg} \mathrm{g}^{-1}\right)$} & \multicolumn{4}{|c|}{ Langmuir isotherm } & \multicolumn{3}{|c|}{ Freundlich isotherm } \\
\hline & $q_{\max }\left(\mathrm{mg} \mathrm{g}^{-1}\right)$ & $K_{L}\left(\mathrm{~L} \mathrm{mg}^{-1}\right)$ & $r$ & $R_{L}$ & $1 / \mathrm{n}$ & $P\left(\mathrm{~L} \mathrm{mg}^{-1}\right)$ & $r$ \\
\hline 9.04 & 24.21 & 0.005 & 0.9640 & $0.81-0.98$ & 1.26 & 0.034 & 0.9897 \\
\hline
\end{tabular}

unfavorable; if the $R_{L}$ is equal to 1 , it indicates a linear isotherm; and if the value results in $0<R_{L}<1$, it indicates a favorable adsorption. Finally, the $R_{L}$ value is equal to 0 , which means that the process is irreversible (Wan Ngah et al. 2002).

The Freundlich isotherm is related to the multilayer of the adsorbed substance on heterogeneous surfaces. For this isotherm, a useful empirical equation is used to describe these multilayer adsorption systems (Bagda et al. 2013; Souza et al. 2016):

$q_{e}=K_{F} C_{e}^{1 / n}$

where $K_{F}$ and $n$ are constants related to the Freundlich adsorption capacity and intensity, respectively. This equation can be written in linear form:

$\log \left(q_{e}\right)=\log \left(K_{\mathrm{F}}\right)+\frac{1}{n} \log \left(C_{e}\right)$

The Langmuir isotherm model is related to adsorption processes in monolayers, in which adsorption occurs at specific sites of the adsorbent (Langmuir 1916), where the specific interaction of phosphate with certain functional groups present on the surface of the humina could occur. This model assumes that once a phosphate ion occupies a site, no further sorption can take place at that site (Voudrias et al. 2002).

The Freundlich isotherm model is associated with the description of heterogeneous systems (Freundlich 1906). This profile is suitable for a system characterized by the higher degree of heterogeneity in the interaction process during the adsorption process. In this situation, phosphate could interact with different chemical groups, increasing the efficiency of the interaction process.

From the results obtained in Fig. 4 and Table 1, it was observed that the phosphate adsorption process with humin responds better to the Freundlich model. Since phosphate is derived from a weak acid, the different species present in solution (depending on the $\mathrm{pH}$ ) may interact with varied groups on the heterogeneous surface of the humin. This is possibly due to relation of the Freundlich isotherm with multilayer of the adsorbed substance on the heterogeneous surfaces. In addition, the absorption is favored according to the increase in the phosphate concentration (Fig. 4 and Table 1).

In addition, comparing these results with the literature (Table 3 ), the humin adsorption capacity for phosphate presented an excellent performance considering the amount of humin (mg), the equilibrium time, and phosphate concentration. Some studies have used times in the timescale, adsorbent masses in grams, and high concentrations of phosphate. Thus, the humin was equivalent or better based on the amount of phosphate adsorbed compared with natural zeolite, goethite, $\mathrm{Nb}_{2} \mathrm{O}_{5} \cdot \mathrm{nH}_{2} \mathrm{O}, \mathrm{Fe}-\mathrm{Al}$-bentonite, soil (xanthic ferralsol), soil (ferralsol), and magnetite $\mathrm{Fe}_{3} \mathrm{O}_{4} \cdot \mathrm{SiO}_{2}$, showing the potential of this natural material.

\subsection{Humin Application in Domestic Effluent Samples}

After evaluation of the humin-phosphate interaction, the ability of this material to retain phosphate and its potential to act as a natural adsorbent was observed. In this sense, humin was applied in a real sample of domestic wastewater collected in São Paulo State (Brazil). The experiments were performed in the original effluent $\mathrm{pH}$ and also at $\mathrm{pH} 4.0$ (optimum $\mathrm{pH}$ of adsorption, according to previous experiments). The kinetic profiles for phosphate concentration reduction in wastewater at natural $\mathrm{pH}$ and at $\mathrm{pH} 4.0$ (adjusted) are shown in Fig. 5.

The total concentration of free phosphate in the effluent was $5.92 \pm 0.10 \mathrm{mg} \mathrm{L}^{-1}$ which is greater in relation to the current legislation in Brazil (Brasil 2011). After humin was added to domestic wastewater, the maximum reduction occurred where the phosphate concentration was around $16 \%$ after $180 \mathrm{~min}$ of contact at $\mathrm{pH} 4.0$. These results differ from those 
Table 3 Phosphate adsorption capacity $(q)$ from some adsorbents reported in the literature

\begin{tabular}{|c|c|c|c|c|c|c|}
\hline Material & $\mathrm{pH}$ & $\begin{array}{l}\text { Equilibrium } \\
\text { time }\end{array}$ & Mass & $\begin{array}{l}\text { Maxima phosphate } \\
\text { concentration } \\
\text { used }\left(\mathrm{mg} \mathrm{L}^{-1}\right)\end{array}$ & $\begin{array}{l}q \\
\left(\mathrm{mg} \mathrm{g}^{-1}\right)\end{array}$ & References \\
\hline Natural zeolite & - & $48 \mathrm{~h}$ & $3 \mathrm{~g}$ & 500 & 2.15 & Sakadevan and Bavor 1998 \\
\hline Goethite & 5.0 & 3 days & $2.0 \mathrm{mg}$ & 22 & 27.5 & Borggaard et al. 2005 \\
\hline $\mathrm{Nb}_{2} \mathrm{O}_{5} \cdot n \mathrm{H}_{2} \mathrm{O}$ & 2.0 & $30 \mathrm{~min}$ & $100 \mathrm{mg}$ & 1.0 & 0.22 & Rodrigues and Silva 2009 \\
\hline Iron-hydroxide eggshell & 7.0 & $4 \mathrm{~h}$ & $750 \mathrm{mg}$ & 53 & 14.5 & $\begin{array}{l}\text { Mezenner and Bensmaili } \\
2009\end{array}$ \\
\hline $\begin{array}{l}\text { Al-bentonite } \\
\text { Fe-bentonite }\end{array}$ & 3.0 & $6 \mathrm{~h}$ & $100 \mathrm{mg}$ & 60 & $\begin{array}{l}12.7 \\
11.2\end{array}$ & Yan et al. 2010 \\
\hline Fe-Al-bentonite & & & & & 10.5 & \\
\hline $\begin{array}{l}\text { Bentonite-humic acid } \\
\text { composite }\end{array}$ & 7.0 & $24 \mathrm{~h}$ & $20 \mathrm{mg}$ & 20 & 26.5 & Zamparas et al. 2013 \\
\hline Soil (xanthic ferralsol) & 4.4 & $24 \mathrm{~h}$ & $1 \mathrm{~g}$ & 200 & 1.84 & Guedes et al. 2016 \\
\hline Soil (ferralsol) & 3.8 & & & & 0.82 & \\
\hline $\begin{array}{l}\text { Magnetita }\left(\mathrm{Fe}_{3} \mathrm{O}_{4}\right) \\
\mathrm{Fe}_{3} \mathrm{O}_{4} \cdot \mathrm{SiO}_{2}\end{array}$ & - & $24 \mathrm{~h}$ & $100 \mathrm{mg}$ & 200 & $\begin{array}{c}11.2 \\
1.20\end{array}$ & Lai et al. 2016 \\
\hline $\begin{array}{l}\mathrm{Fe}_{3} \mathrm{O}_{4} \cdot \mathrm{SiO}_{2} \text { with lanthanum } \\
\text { oxide }\end{array}$ & - & & & & 27.8 & \\
\hline Humin & 4.0 & $20 \mathrm{~min}$ & $100 \mathrm{mg}$ & 100 & 9.04 & This work \\
\hline
\end{tabular}

found previously, when using the phosphate adsorption test, observing the retention rate of $32 \%$. However, in real systems such as municipality wastewater samples, there are other substances in the medium that compete with the phosphate sites for complexing/ retention present in humin, which may be associated with the decrease in retention in real systems.

When evaluating the decrease in phosphate concentration by humin in the natural $\mathrm{pH}$ of the wastewater $(\mathrm{pH}=7.0)$, we observed a maximal phosphate reduction of approximately $13 \%$ after 180 min of contact (Fig. 5b). In general, in adjusted $\mathrm{pH}$ to 4.0 , there was a better adsorption than in the original effluent $\mathrm{pH}$. This may be associated with the distribution of other phosphorus species with an increasing $\mathrm{pH}$, and the influence of other chemical species derived from acids or weak bases present in the evaluated wastewater. Furthermore, the $\mathrm{pH}$
Fig. 5 The effect of phosphate concentration in the wastewater with the addition of humin in $\mathbf{a}$ $\mathrm{pH} 4.0$ (adjusted) and $\mathbf{b}$ the natural $\mathrm{pH}$ of the effluent
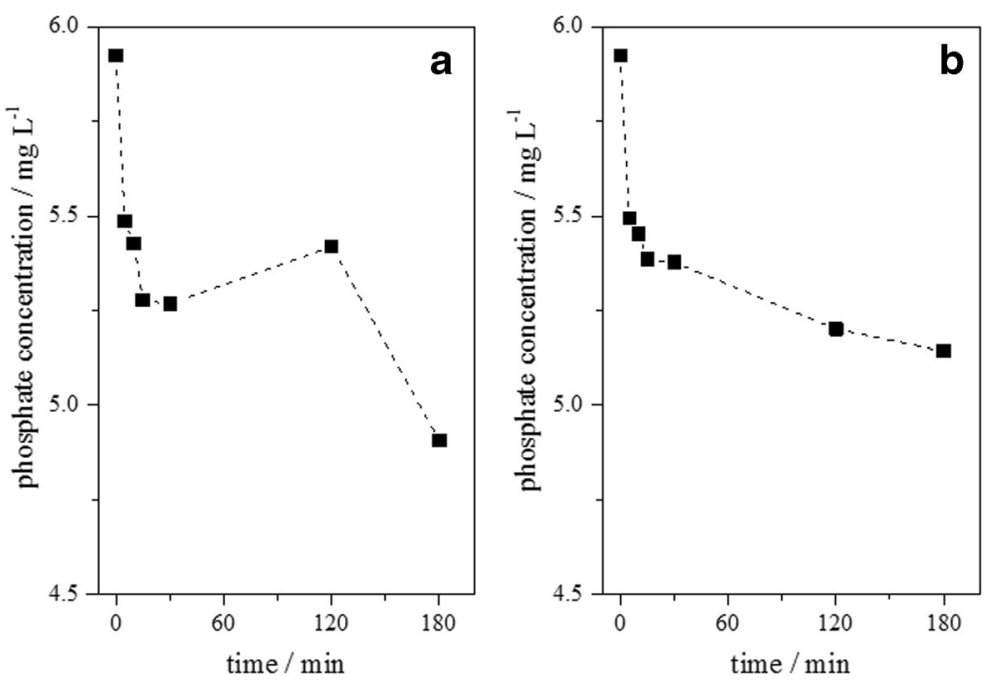
changes the distribution of positive and negative charges on the humin surface, where at $\mathrm{pH} 4.0$ preferably positive charges were found contributing to the adsorption process $(\mathrm{pH}$ of the medium $<$ $\left.\mathrm{pH}_{\mathrm{PZC}}\right)$.

These results highlight the potential use of humin as a natural adsorbent. Humin showed the ability to retain phosphorus species of the effluent, thus reducing the impact to the environment. To present heterogeneous characteristics, humin can be easily separated from the effluent and subsequently applied in agriculture providing phosphorus availability (essential macronutrient in different cultures); without negative impact to the soil, a humin is a natural material.

\section{Conclusions}

Studies about the interaction of humin-phosphate demonstrated that humin had the potential to be an environmental remedial in effluent reducing the amount of phosphate added to the wastewater. The results show that the phosphate adsorption process depends on the $\mathrm{pH}$ and at $\mathrm{pH} 4.0$ occurring at maximum retention. This possibly occurred due to distribution of phosphate ions in the $\mathrm{pH}$ values evaluated. At $\mathrm{pH} 4.0$, it is present in the preferred form of dihydrogen phosphate, presenting only a negative charge. This may explain the greater interaction with the surface of humin. The humin has negative charges, then the repulsion will be smaller among them and different from other phosphorus species (monohydrogen phosphate), which have two negative charges. Taking into consideration the systems studied, the adsorption kinetics followed the mechanism of a pseudo-second order according to the best fit model at $\mathrm{pH}$ 4.0. The phosphate adsorption on humin was reached from the balance of $15 \mathrm{~min}$ of contact in the humin-phosphate system. Considering the adsorption process, the best isotherm model was Freundlich and the humin complexing ability in relation to phosphate was $11.53 \mathrm{mg} \mathrm{g}^{-1}$. For use in wastewater, the results showed that there was phosphate retention, about $16 \%$ showing that the humin has a potential for phosphate retention reducing environmental impact. The great interest in this material is its agricultural use as a source of organic material and phosphorus.
Acknowledgements The authors are grateful to the National Council for Scientific and Technological Development (CNPq Process 478361/2013-0) for the financial support provided.

\section{References}

Azizian, S. (2004). Kinetic models of sorption: a theoretical analysis. Journal of Colloid and Interface Science, 276(1), 4552.

Bagda, E., Ersan, M., \& Bagda, E. (2013). Investigation of adsorptive removal of tetracycline with sponge like, Rosa canina gall extract modified, polyacrylamide cryogels. Journal of Environmental Chemical Engineering, 1(4), 1079-1084.

Batista, A. P. S., Romão, L. P. C., \& Arguelho, M. L. P. M. (2009). Biosorption of $\mathrm{Cr}$ (III) using in natura and chemically treated tropical peats. Journal of Hazardous Materials, 163(2), 517523.

Borggaard, O. K., Raben-Lange, B., Gimsing, A. L., \& Strobel, B. W. (2005). Influence of humic substances on phosphate adsorption by aluminium and iron oxides. Geoderma, 127(3-4), 270-279.

Botero, W. G., Oliveira, L. C., Rocha, J. C., Rosa, A. H., \& Santos, A. (2010). Peat humic substances enriched with nutrients for agricultural applications: competition between nutrients and non-essential metals present in tropical soils. Journal of Hazardous Materials, 177(1-3), 307-311.

Botero, W. G., Oliveira, L. C., Cavagis, A. D. M., Rosa, A. H., Rocha, J. C., \& Santos, A. (2013). Influence of the extractant on the complexing capacity of humic substances from peat for macro and micronutrients using continuous flow: agricultural application and environmental impacts. Journal of the Brazilian Chemical Society, 24(12), 2015-2020.

Brasil (2011). Resolution CONAMA 430/2011. http://www.mma. gov.br/port/conama. Accessed 10.11.16.

Buffle, J., \& Staub, C. (1984). Measurement of complexation properties of metal-ions in natural conditions by ultrafiltration-measurement of equilibrium-constants for complexation of zinc by synthetic and natural ligands. Analytical Chemistry, 56(14), 2837-2842.

Burba, P., Van Den Bergh, J., \& Klockow, D. (2001). On-site characterization of humic-rich hydrocolloids and their metal loads by means of mobile size-fractionation and exchange techniques. Fresenius Journal of Analytical Chemistry, 371(5), 660-669.

Cerqueira, S. C. A., Romao, L. P. C., Lucas, S. C. O., Fraga, L. E., Simoes, M. L., Hammer, P., Lead, J. R., Mangoni, A. P., \& Mangrich, A. S. (2012). Spectroscopic characterization of the reduction and removal of chromium (VI) by tropical peat and humin. Fuel, 91(1), 141-146.

Contreras, C., De La Rosa, G., Peralta-Videa, J. R., \& GardeaTorresdey, J. L. (2006). Lead adsorption by silicaimmobilized humin under flow and batch conditions: assessment of flow rate and calcium and magnesium interference. Journal of Hazardous Materials, 133(1-3), 79-84.

Cunha, G. C., Goveia, D., Romao, L. P. C., \& Oliveira, L. C. (2015). Effect of the competition of $\mathrm{Cu}(\mathrm{II})$ and $\mathrm{Ni}$ (II) on 
the kinetic and thermodynamic stabilities of $\mathrm{Cr}$ (III)-organic ligand complexes using competitive ligand exchange (EDTA). Journal of Environmental Management, 154, 259-265.

De La Rosa, G., Peralta-Videa, J. R., \& Gardea-Torresdey, J. L. (2003). Utilization of ICP/determination of volatile organic compounds in drinking water. Chemosphere, 45(3), 275284.

Freundlich, H. M. F. (1906). Over the adsorption in solution. Journal of Physical Chemistry, 57, 385-470.

Goveia, D., Melo, C. D. A., Oliveira, L. K. D., Fraceto, L. F., Rocha, J. C., Dias Filho, N. L., \& Rosa, A. H. (2013). Adsorption and release of micronutrients by humin extracted from peat samples. Journal of the Brazilian Chemical Society, 24(5), 721-730.

Guedes, R. S., Melo, L. C. A., Vergutz, L., Rodriguez-Vila, A., Covelo, E. F., \& Fernandes, A. R. (2016). Adsorption and desorption kinetics and phosphorus hysteresis in highly weathered soil by stirred flow chamber experiments. Soil and Tillage Research, 162, 46-54.

Gustafsson, J.P. (2016). Visual MINTEQ, ver. 3.1. Stockholm: Royal Institute of Technology, Div. of Land and Water Resources Engineering. Available at: https://vminteq.lwr. kth.se/visual-minteq-ver-3-1/.

Ho, Y. S., \& McKay, G. (1999). The sorption of lead(II) ions on peat. Water Research, 33(2), 578-584.

Ho, Y. S., Ng, J. C. Y., \& McKay, G. (2000). Kinetics of pollutant sorption by biosorbents: review. Separation and Purification Methods, 29(2), 189-232.

Jacundino, J. S., Santos, O. S., Santos, J. C. C., Botero, W. G., Goveia, D., Carmo, J. B., \& Oliveira, L. C. (2015). Interactions between humin and potentially toxic metals: Prospects for its utilization as an environmental repair agent. Journal of Environmental Chemical Engineering, 3(2), 708715.

Lai, L., Xie, Q., Chi, L., Gu, W., \& Wu, D. (2016). Adsorption of phosphate from water by easily separable $\mathrm{Fe}_{3} \mathrm{O}_{4} @ \mathrm{SiO}_{2}$ core/ shell magnetic nanoparticles functionalized with hydrous lanthanum oxide. Journal of Colloid and Interface Science, 465, 76-82.

Langmuir, I. (1916). The constitution and fundamental properties of solids and liquids. Part I. Solids. Journal of the American Chemical Society, 38, 2221-2295.

Manahan, S., \& Manahan, S. E. (2009). Environmental chemistry. New York: Press Taylor \& Francis.

Mezenner, N. Y., \& Bensmaili, A. (2009). Kinetics and thermodynamic study of phosphate adsorption on iron hydroxideeggshell waste. Chemical Engineering Journal, 147(2-3), $87-96$.

Millier, H. K. G. R., \& Hooda, P. S. (2011). Phosphorus species and fractionation e why sewage derived phosphorus is a problem. Journal of Environmental Management, 92(4), 1210-1214.

Ninfant'eva, T. I., Shkinev, V. M., Spivakov, B. Y., \& Burba, P. (1999). Membrane filtration studies of aquatic humic substances and their metal species: a concise overview. Part 2. Evaluation of conditional stability constants by using ultrafiltration. Talanta, 48(2), 257-267.

Nkhili, E., Guyot, G., Vassal, N., \& Richard, C. (2012). Extractability of water-soluble soil organic matter as monitored by spectroscopic and chromatographic analyses.
Environmental Science and Pollution Research, 19(6), 2400-2407.

Paula Filho, F. J., Marins, R. V. (2004). Distribuição e partição geoquímica de fósforo em sedimentos estaurinos do rio Jaguaribe/CE - Fortaleza-CE. http://www.repositorio.ufc. $\mathrm{br} /$ handle/riufc/1311. Accessed 20 June 2016.

Raij, B. V., Quaggio, J. A., Cantarella, H., Ferreira, M. E., Lopes, A. S., Bataglia, O. C. (1987). Análise química do solo para fins de fertilidade. Campinas: Fundação Cargill.

Rice, J. (2001). Humin. Soil Science, 166(11), 848-857.

Rocha, J. C., Rosa, A. H., \& Cardoso, A. A. (2009). Introduction to environmental chemistry. Porto Alegre: Bookman.

Rodrigues, L. A., \& Silva, M. L. C. P. (2009). Adsorption of phosphate ions on hydrous niobium oxide. Quimica Nova, 32(5), 1206-1211.

Romao, L. P. C., Castro, G. R., Rosa, A. H., Rocha, J. C., Padilha, P. M., \& Silva, H. C. (2003). Tangencial flow ultrafiltration: a versatile metodology for determination of complexation parameters in refractory organic matter from brazilian water and soil samples. Analytical and Bioanalytical Chemistry, 375(8), 1097-1100.

Rosa, A. H., Rocha, J. C., \& Furlan, M. (2000). Humic substances of peat: study of the parameters that influence on the process of alkaline e extraction. Quimica Nova, 23(4), 472-476.

Rosa, A. H., Goveia, D., Bellin, I. C., Lessa, S. S., Dias Filho, N. L., \& Padilha, P. M. (2006). New analytical procedure based on cellulose bag and ion exchanger with $p$-aminobenzoic groups for differentiation of labile and inert metals species in aquatic systems. Analytical and Bioanalytical Chemistry, 386(7-8), 2153-2160.

Sakadevan, K., \& Bavor, H. J. (1998). Phosphate adsorption characteristics of soils, slags and zeolite to be used as substrates in constructed wetland systems. Water Research, 32(2), 393-399.

Sargentini Jr., E., Rocha, J. C., Rosa, A. H., Zara, L. F., \& Santos, A. (2001). Aquatic humic substances: molecular size fractionation and characterization of inner rearrangements after metal ions complexation. Química Nova, 24(3), 399-344.

Souza, S. O., Oliveira, L. C., Cavagis, A. D. M., \& Botero, W. G. (2014). Cyanogenic residues: environmental impacts, complexation with humic substances, and possible application as biofertilizer. Water, Air and Soil Pollution, 225, 2223-2233.

Souza, S. O., Silva, M. M., Santos, J. C. C., Oliveira, L. C., Carmo, J. B., \& Botero, W. G. (2016). Evaluation of different fractions of the organic matter of peat on tetracycline retention in the environmental conditions: in vitro studies. Journal of Soils and Sediments, 16(6), 1764-1775.

Standard Methods for the Examination of Water \& Wastewater (2005). New York: American Public Health Association.

Voudrias, E., Fytianos, K., \& Bozani, E. (2002). Sorption desorption isotherms of dyes from aqueous solutions and wastewaters with different sorbent materials. Global NEST Journal, 4(1), 75-83.

Wan Ngah, W. S., Endud, C. S., \& Mayanar, R. (2002). Removal of copper (II) ions from solution onto chitosan and crosslinked chitosan beads. Reactive and Functional Polymers, 50(2), 181-190. 
Winarso, S., Sulistyanto, D., \& Handayanto, E. (2011). Effects of humic compounds and phosphate solubilizing bacteria on phosphorus availability in an acid soil. Journal of Ecology and the Natural Environment, 3(7), 232-240.

Yan, L., Xu, Y., Yu, H., Xin, X., Wei, Q., \& Du, B. (2010). Adsorption of phosphate from aqueous solution by hydroxy-aluminum, hydroxy-iron and hydroxy-iron-aluminum pillared bentonites. Journal of Hazardous Materials, 179(13), 244-250.
Zamparas, M., Drosos, M., Georgiou, Y., Deligiannakis, Y., \& Zacharias, I. (2013). A novel bentonite-humic acid composite material Bephos ${ }^{\mathrm{TM}}$ for removal of phosphate and ammonium from eutrophic waters. Chemical Engineering Journal, 225(1), 43-51.

Zhang, J., He, M., \& Shi, Y. (2009). Comparative sorption of benzo $[\alpha]$ phrene to different humic acids and humin in sediments. Journal of Hazardous Materials, 166(2-3), 802-809. 